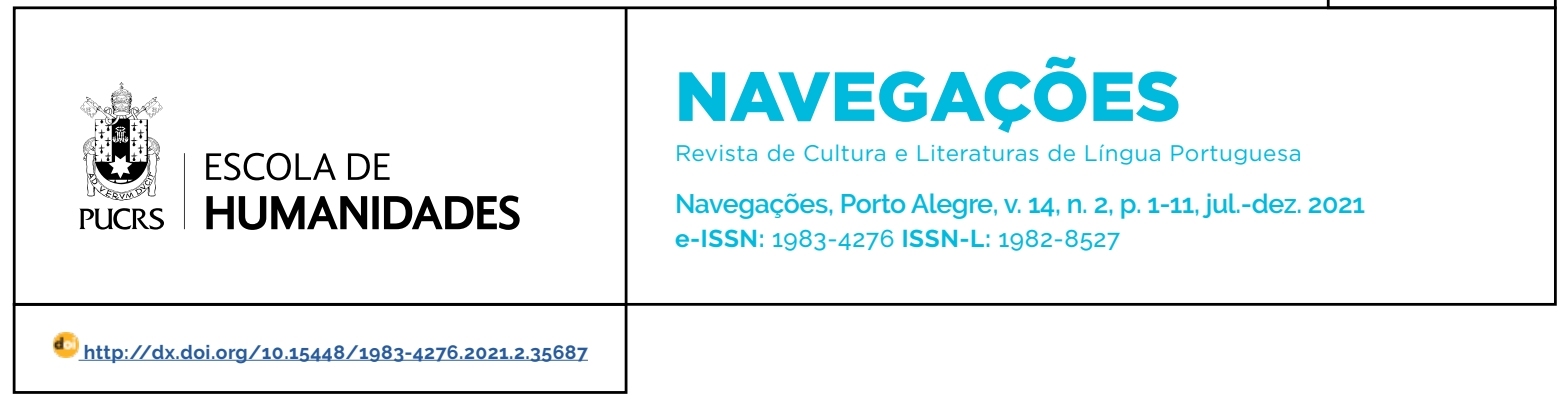

SEÇÃO: ENSAIOS

\title{
O entrelaçar da história e da ficção em Só as mulheres sangram
}

The interlacing of history and fiction in Só as mulheres sangram

\section{Elizane Souza dos \\ Santos Henriques ${ }^{1}$}

orcid.org/0000-0001-9094-9145

santoselizane74@gmail.com

\section{Inara de Oliveira}

Rodrigues $^{1}$

orcid.org/0000-0001-8950-7374

inarabr23@gmail.com

Recebido em: 14 set. 2019

Aprovado em: 5 ago. 2021

Publicado em: 16 dez. 2021.

\section{(c) (1)}

Artigo está licenciado sob forma de uma licença Creative Commons Atribuicão 4.0 Internacional.
Resumo: Neste estudo, problematizamos as relações entre a história e a ficção em quatro contos que compõem a narrativa afro-brasileira Só as mulheres sangram, escrita por Lia Vieira (2017). A obra aponta à vulnerabilidade social da população negra no Brasil e às heranças escravagista, colonial e patriarcal. Para a abordagem de tais questões, a pesquisa, de cunho bibliográfico e analítico, tem como base teórica as relações entre a história e a literatura (PESAVENTO, 2003: RICOUER, 1997; GINZBURG, 2007); a concepção de literatura afro-brasileira (DUARTE, 2007); e a Teoria do conto (GOTLIB, 2012; MARIA, 2004). A análise permitiu concluir que os contos mantêm diálogo constante com a realidade histórica na qual se inserem. Ao dar ênfase à afetividade e à ancestralidade do povo negro, bem como à emancipação feminina, essas narrativas valorizam a identidade e o lócus enunciativo desses sujeitos, fomentando, assim, reflexões sobre a necessidade de enfrentamento das desigualdades e dos fluxos hegemônicos.

Palavras-chave: Feminismo negro. Literatura afro-brasileira. Questões identitárias.

Abstract: In this study, we problematize the relations between history and fiction in four short stories that compose the afro-brazilian narrative Só as mulheres sangram, written by Lia Vieira (2017). The work points to the social vulnerability of the black population in Brazil, and to slavery, colonial and patriarchal heritages. In order to solve these questions, the research, bibliographical and analytical, has as its theoretical basis the relations between History and Literature (PESAVENTO, 2003; RICOUER, 1997; GINZBURG, 2007); the conception of Afro-Brazilian literature (DUARTE, 2007); and Theory of the Tale (GOTLIB, 2012; MARIA, 2004). The analysis allowed us to conclude that the stories maintain constant dialogue with the historical reality in which they are inserted. By emphasizing the affectivity and ancestry of black people, as well as female emancipation, such narratives value the identity and enunciative locus of these subjects, thus encourages reflection on the need to address inequalities and hegemonic flows.

Keywords: Black feminism. Afro-Brazilian Literature. Identity issues.

\section{Introdução}

Problematizamos, neste trabalho, as relações entre a história e a ficção, dois campos entrelaçados na literatura afro-brasileira contemporânea, tomando-se por exemplar o livro de contos Só as mulheres sangram, de Lia Vieira (2017). Para tanto, organizamos o estudo em dois momentos: no primeiro, tecemos breves considerações sobre algumas das principais implicações, no campo literário, das relações entre história e ficção e apresentamos a obra, a produção literária da autora, assim como aspectos basilares sobre a definição e história da literatura afro-brasileira. No 
segundo momento, analisamos quatro das nove narrativas que compõem a obra literária referida: "Foram Sete", "Maria Déia", "Operação Candelária" e "Os limites do moinho", selecionadas pela maior afinidade temática com a discussão aqui pretendida, ou seja, o diálogo que neles se apresenta entre a ficção e a história, pontuando-se os seus respectivos desdobramentos.

A existência de vertentes literárias brasileiras que ressaltam a identidade negra pressupõe a quebra do silenciamento imposto pelos processos históricos de exploração e dominação, abrindo espaço à representatividade afrodescendente na literatura. Nesse sentido, a obra de Lia Vieira aponta, entre outros temas, para a vulnerabilidade social da população negra no Brasil, questiona a violência policial, bem como alerta para as consequências das heranças escravagista e colonial em nosso país.

Para o desenvolvimento da análise, a partir de pesquisa bibliográfica e analítica, tomamos por base os estudos de Ricoeur (1997), Ginzburg (2007) e Pesavento (2003) sobre as relações entre a história e a literatura; as definições de Duarte (2007) sobre a literatura afro-brasileira; e os apontamentos de Oliveira e Rodrigues (2016) sobre os principais (e sintéticos) aspectos da história da literatura afro-brasileira.

Entendemos que a abordagem aqui proposta se justifica, assim, por enfocar a legitimidade do lugar de fala das pessoas negras enquanto espaço de potência e ressignificação de visões de mundo. Trata-se da afirmação de olhares que comportam urgência em contestar a concepção universalizante e estigmatizada da mulher, da negritude e de suas identidades.

\section{A literatura afro-brasileira e a obra de Lia Vieira: entre a história e a ficção}

A discussão sobre as relações entre a história e a ficção constitui-se em tema aparentemente inesgotável no campo dos estudos literários. Adotamos, como ponto de partida, a concepção de Ricoeur (1997, p. 316), para quem o entrelaçamento da história com a ficção é a "estrutura fundamental, tanto ontológica quanto episte- mológica" através da qual, ambas, concretizam as suas significações, a fim de promoverem a reconfiguração do tempo.

Sem negar a especificidade que a caracteriza, o mesmo teórico aponta o pertencimento da narrativa histórica, antes de tudo, à ordem da narração. De modo que, em suas intencionalidades, a ficção e a história guardam referências com o mundo vivido (RICOEUR, 1997). Destacam-se, assim, as suas proximidades, pois ambas se configuram enquanto narrativas que utilizam recursos distintos para tecer realidades, ao trazerem à cena um referencial do mundo, ainda que seja para negar ou transmutar o que está representado.

Já dentre as suas diferenças, sobressaem questões metodológicas e os recursos empregados para narrar a vida: enquanto a história apresenta ligação com o passado mais ou menos distante, persegue os traços do referente e se detém no compromisso com as fontes, a literatura pode recorrer a incontáveis recursos que intensificam a ficcionalidade dos acontecimentos narrados, além de poder projetar-se em um tempo futuro (PESAVENTO, 2003). Sobretudo, há muito já foi demarcado que, no caso de narrativas históricas e ficcionais, não se trata de identificarmos o que é verdadeiro ou falso, tanto mais no caso do texto literário, porque este também pode suscitar "novas significações históricas, com derivações ideológicas" (MATA, 1993, p. 45) que influem na percepção da realidade narrada.

Nessa perspectiva, são tênues as linhas de separação entre a história e a ficção (FONSECA, 2015), sendo que, para compreendermos a obra literária selecionada neste trabalho, de acordo com a análise proposta, é necessário observarmos que, no campo literário em que ela se insere, a história se constitui, muitas vezes, em fundamento importante por não figurar apenas como contexto, mas também como elemento basilar do enredo, sendo-lhe atribuida a força de protagonista, diante da qual observamos os vestígios/rastros que tornam presente algo do passado (RICOUER, 1997). De modo análogo, Carlo Ginzburg (2007) aponta a relevância dos sinais, enquanto pistas de um ocorrido. Ambos, 
sinais e rastro, expressam a demarcação de uma passagem (ou evento) no tempo e no espaço.

Dessa maneira, para a história, o rastro aproxima-se da noção de documento, quando guiado por perguntas, enquanto, na literatura, assume a importância de indício de uma presença, ao narrar um passado que ainda se faz presente. De toda forma, a noção de rastro completa o seu sentido no encontro com a imaginação. Especificamente em relação à literatura afro-brasileira, a história deve ser observada pelo percurso do grupo étnico que lhe dá sentido: as pessoas negras, que sofrem as consequências de um passado colonial escravista ainda presentes na sociedade brasileira.

De modo geral, entende-se, assim, que a literatura afro-brasileira tem a proposta de abarcar temas social e culturalmente pertinentes ao povo negro em diáspora, além da utilização de recursos estéticos e linguísticos para a valorização dessa diversidade. Segundo Duarte (2007), compreende principalmente o enfrentamento da herança colonial-escravagista, tendo como nascente, na prosa, o romance Úrsula, (1859), escrito por Maria Firmina dos Reis e, na poesia, registram-se os poemas de Paula Brito e a obra Trovas Burlescas, de Luiz Gama. Em Úrsula, o protagonista é denominado Túlio, um negro escravizado que tem atos de compaixão e solidariedade com um cavaleiro branco, a quem salva a vida. Percebemos, nessa abordagem, a subversão realizada pela autora, pois, na lógica preconizada pelo cânone, seria o homem branco o salvador que apareceria para "solucionar" os problemas. Com efeito, segundo Marques, apresentadora/ensaista do romance, a obra traz à tona "[...] uma representação de mundo desestabilizadora do próprio mundo, para fazer emergir um discurso crítico ao patriarcado e ao escravagismo no Brasil, na condição de forasteira de dentro" (REIS, 2018, p. 46, grifo da autora).

Nessa perspectiva, percebemos a etnicidade contextualizada da produção designada por Assis
Duarte (2007) de afro-brasileira, caracterizada em cinco elementos: a temática; a autoria; o ponto de vista; a linguagem e o público-alvo. Com essas características, o(a) negro(a) é o tema principal da literatura afro-brasileira; a escrita é proveniente de autores que se identificam e são identificados enquanto afro-brasileiros(as), ${ }^{2}$ já o ponto de vista é revelado pela demonstração de uma compreensão do mundo ligada à história e à cultura do povo negro e africano em diáspora. Em relação à linguagem, se estabelece uma discursividade específica, marcada pela expressão de ritmos e significados provenientes da cultura negra e afro-brasileira. Por fim, o quinto fator é a formação/existência de um público leitor afrodescendente e, desse modo, "essa literatura não só existe como se faz presente nos tempos e espaços históricos de nossa constituição enquanto povo; não só existe como é múltipla e diversa" (DUARTE, 2007, p. 1).

A partir desses elementos identificadores, considerados em conjunto, essa produção literária promove rasuras no cânone e valoriza as diferenças, além de (re)apresentar criticamente a história, desvelando/denunciando as dores, as lutas e as conquistas do povo negro. Trata-se um processo de resistência cultural que, segundo Oliveira e Rodrigues (2016), encontra relevantes registros desde o século $X I X,{ }^{3}$ com a publicação de contistas como José do Patrocínio, Machado de Assis e Antônio Gonçalves Crespo.

Não foram poucos, entretanto, os percalços para a publicação das narrativas literárias afro-brasileiras. Entre outros exemplos, podemos citar a desintegração do grupo Frente Negra Brasileira (FNB), em 1937, que, de acordo com Oliveira e Rodrigues (2016), era a mais efetiva associação negra da época e obteve destaque no Brasil e no exterior por sua atuação para garantir os direitos civis da população afrodescendente, sendo citada e comentada na imprensa afro-americana

\footnotetext{
2 Sublinhamos nossa compreensão de que se trata de um campo em que se inserem produções literárias de pessoas negras: "[...] a autoria há que estar conjugada intimamente ao ponto de vista. Literatura é discursividade e a cor da pele será importante enquanto tradução textual de uma história própria ou coletiva" (DUARTE [2007], grifo do autor) Disponivel em: http://www.letras.ufmg.br/literafro/artigos/artigos-teorico-conceituais/148-eduardo-de-assis-duarte-por-um-conceito-de-Literatura-afro-brasileira. Acesso em: 12 abr. 2019). 3 Restringimo-nos aqui, por certo, à produção escrita afro-brasileira. Diversos trabalhos relevantes abordam a riqueza e importância dos contos afro-brasileiros de base e tradição oral que, no entanto, não estão no horizonte deste estudo.
} 
da década de 1930 (DOMINGUES, 2013, p. 156). A situação agravou-se quando a publicação $A$ voz da raça, pertencente à FNB, também foi desativada, gerando novas dificuldades para a publicação e circulação dos textos produzidos pelos(as) intelectuais negros(as) da época.

Esse quadro foi alterado nas últimas décadas do século $X X$, com o surgimento da coletânea de prosa e poesia intitulada Cadernos Negros publicação cooperativa e anual, administrada pelo grupo paulista Quilombhoje Literatura. Especificamente após o ano de 1978, as edições da coletânea passaram a abarcar questões culturais, religiosas e históricas do povo afro-brasileiro, contribuindo para a difusão de conhecimentos acerca da vivência negra brasileira. Assim, entre os anos 1979 e 2016, "[...] houve um significativo aumento de publicações autorais de contos afro-brasileiros, totalizando 67 livros, bem como das publicações de romances, que totalizaram 39 publicações" (OLIVEIRA; RODRIGUES, 2016, p. 101). Ou seja, a experiência exitosa da publicação coletiva dos Cadernos Negros permitiu que várias escritoras participantes do grupo publicassem posteriormente obras individuais (sendo contos e/ou romances), a exemplo de Esmeralda Ribeiro, Geni Guimarães e Miriam Alves. ${ }^{4}$

Em perspectiva mais contemporânea, autores(as) como Cuti (pseudônimo de Luiz Silva), Edimilson de Almeida Pereira, Solano Trindade e Mãe Beata de Yemonjá são frequentemente citados pela valorização da identidade negra imersa em suas obras. Assim também, no século $X X I$, dentre outras produções, destacam-se: Um defeito de cor, de Ana Maria Gonçalves (2006); Mandingas da mulata velha na cidade nova, de Nei Lopes (2009); Só por hoje vou deixar o meu cabelo em paz, de Cristiane Sobral (2016); Olhos d'água, de Conceição Evaristo (2016), que promovem a afirmação da literatura afro-brasileira. Felizmente, a lista de autoras que abordam as diversas temáticas relacionadas à população negra e afrodescendente no Brasil de hoje tem se ampliando, podendo-se citar, de forma muito incompleta, os trabalhos de Alzira Rufino, Rita Santana, Livia Natália, Cidinha da Silva e Ryane Leão, dentre outras importantes vozes

Nessa visada contemporânea, destacamos a obra de Lia Vieira (2017), natural do Rio de Janeiro, de nome civil Eliana Vieira, que, além de poeta, artista plástica, e economista, participa da militância do movimento negro e do movimento de mulheres. Possui variada publicação de contos, poemas e coletâneas no Brasil e no exterior, podendo-se ressaltar os livros: Eu, mulher - mural de poesias (1990); Chica da Silva - a mulher que inventou o mar (2001) e Só as mulheres sangram, objeto de nossa análise, incluindo participações importantes na série Cadernos Negros. Trata-se, assim, de uma trajetória marcada pelo engajamento na luta por direitos dos(as) negros(as) de existirem enquanto sujeitos políticos e autônomos.

A coletânea de contos Só as mulheres sangramé prefaciada pela reconhecida escritora e professora afro-brasileira Miriam Aparecida Alves, que estreou como uma das autoras do quinto número de $\mathrm{Ca}$ dernos Negros em 1982. No prefácio, ela sublinha, poeticamente, os sentidos do termo 'sangrar' para as mulheres: "estado constante de ser e estar [...] o que talvez nos faça responsável pela criação e procriação. [...] amadas e condenadas, admiradas e ignoradas, que nos fazem sangrar continuidades persistentes" (VIEIRA, 2017, p. 12, grifo da autora). Nesse 'sangrar', portanto, encontram-se os vários sofrimentos da existência, representados por Lia Vieira na trajetória de suas personagens negras, destacando-se as mulheres como protagonistas, ou seja, ganham ênfase as ações desse grupo étnico que sempre esteve subjugado à categoria do "não lugar" (MBEMBE, 2014, p. 130).

Apresentando-se a obra de forma abrangente, ela se constitui de nove narrativas curtas: em duas delas -"A paixão e o vento" e "Provas para o Capitão" - encontramos uma diversidade de temas que vão desde a hipersexualização do corpo da mulher negra e do mito da sexualidade masculina negra inesgotável, à discriminação racial e às irregularidades na aplicação de leis 
brasileiras contra o racismo. Três narrativas curtas refletem sobre a afetividade, as conquistas e os sofrimentos das mulheres negras: em "Rosa da Farinha", a afetividade é abordada por meio da ancestralidade ensinada da avó para neta; em "Os limites do moinho", descortinam-se aspectos da emancipação feminina na vida da protagonista Domingas diante de seu relacionamento amoroso; e, em "Por que Nicinha não veio?", focaliza-se a amizade entre mãe e filha ao vivenciarem - uma dentro, outra fora - a desumanidade do sistema carcerário brasileiro.

As outras quatro histórias denunciam a vulnerabilidade social da população negra: "He Man", protagonizado por Daé, focaliza a pobreza constante e o sentimento de exclusão social da personagem central na tentativa de roubar presentes de Natal para o irmão mais novo; "Operação Candelária" retrata o acontecimento histórico em que foram assassinados jovens negros, apontando a violência policial e a banalização da vida de moradores de rua; "Foram Sete", também em tom de alerta, denuncia a insegurança vivida por mulheres nas favelas e a impunidade nos casos de pedofilia e estupro; já em "Maria Déia", a protagonista relata várias etapas de sua vida, envolvendo preconceito racial e o menosprezo do Estado pela população das comunidades periféricas.

\section{Só as mulheres sangram: contos de uma história no plural}

O primeiro conto escolhido para esta análise, intitulado: "Foram Sete", aborda a violência sexual, a pedofilia e a marginalidade a que são lançadas as mulheres negras das favelas brasileiras. Nele, a personagem Aruanda, pré-adolescente de doze anos, é estuprada pelo vizinho. A narrativa é contada por Luanda, narradora-protagonista e irmã da vítima. Ao longo do enredo, o tom é de denúncia sobre o crime que o vizinho realizava com frequência: "Já outro [dia] clareava, com seu Safa-Onça em minha cabeça. Branco, macho e rico, seu passatempo era descabaçar menininhas. Assim falavam todos, assim sabiam todos, assim calavam todos" (VIEIRA, 2017, p. 71). Demarca-se, nesse fragmento, a impunidade do racismo, do machismo e a condição de classe a garantir a opressão das mulheres pobres e desassistidas, bem como as marcas do sistema escravagista sobre as mulheres negras, que foram e ainda são consideradas como objetos sexuais. Como afirma Angela Davis: "[...] dificilmente havia uma base para 'prazer, afeto e amor', quando os homens brancos, por sua condição econômica, tinham acesso ilimitado ao corpo das mulheres negras" (2017, p. 38).

Nesse quadro, a personagem Safa-Onça pode ser identificada com o retrato do colonizador do tempo da escravidão, quando o estupro era utilizado como forma de dominação e de castigo. Essa dominação continua a ser exercida na atual sociedade brasileira, marcada pelo machismo e racismo. Como referido, o conto vincula-se a um passado que ainda se faz presente (RICOUER, 1997, p. 120), devido à falta de punição em muitos casos de violência sexual, e da vulnerabilidade social, caso em que vivem as irmãs Aruanda e Luanda, bem como a mãe delas, Flor de Liz. A situação de vida da protagonista-narradora representa uma parcela do cotidiano da mulher negra, diversas vezes colocada como o Outro do Outro (RIBEIRO, 2017, p. 38), pois, em relação ao homem branco, à mulher branca e ao homem negro, é colocada em último grau de importância. O trecho a seguir expõe a indignação de Luanda após perceber que a irmã tinha sido violentada:

Eram oito horas quando voltei e lá estava... notei
que a sala virara um tapete escuro. Pude, então,
distinguir Aruanda aninhada no chão. A bichi-
nha nem se mexia. Tive receio de me aproximar.
A vela de seu Sete estava apagada. Me arrepiei.
Fiquei ali. Achei-me perdida. Amaldiçoei baixi-
nho: - Filho da puta! Foi quando o raio cortou os
céus e dividiu meus pensamentos que foram
indo, indo e só voltaram quando os vizinhos
começaram a gritar que eu acabara com seu
Safa-Onça (VIEIRA, 2017, p. 72).

Essa referência à morte do estuprador é fato que encerra o conto. A narrativa não descreve a sequência dramática do estupro nem o momento exato do assassinato, tratando, assim, de forma não espetacularizada a violência. Ao mesmo tempo, permite reconhecer a autoria da morte do violentador pelo facão nas mãos de Luanda: "O trem do esquecimento já fez o passado e, no 
meu trilho de lembranças, só restam o facão e o rosto envelhecido, mas sem lágrimas, [...] de Flor de Liz" (VIEIRA, 2017, p. 73). O facão é, portanto, um rastro que conecta dois momentos marcantes do enredo, o estupro e o assassinato, e "combina, assim, uma relação de significância, [...] vestígio de uma passagem" (RICOEUR, 1997, p. 202) que permanece no tempo presente.

No entanto, a não lembrança dos fatos revela o trauma da narradora e a não premeditação do crime. Deve-se destacar que o sentido de esquecimento como um trem a deslocar-se nos trilhos das lembranças é uma recorrente e importante metáfora no campo da história. Em uma direção positiva, "é um trem riscando trilhos, abrindo novos espaços, acenando muitos braços, embalando nossos filhos", como compôs Pablo Milanés, na Canção para a unidade da América Latina nos anos de 1970, em tom de luta e resistência contra as ditaduras militares que golpeavam os países latino-americanos. Nesse cenário, esse trem dirigia-se ao futuro, e representava a construção de um novo tempo, de solidariedade (os braços em aceno) e paz (o embalo das crianças).

No texto em estudo, porém, Lia Vieira sublinha o lado negativo de se voltar ao passado, quando só se encontra dor e revolta: no deslocamento da memória, agora individual, o esquecimento é condição de sobrevivência - mas, dialeticamente, esse esquecimento, registrado na escrita do conto, torna-se um permanente lembrar da condição dos negros e negras subalternizados(as), marginalizados(as). Assim, pela literatura, presentifica-se a realidade histórica de sujeição e luta, opressão/ resistência, esquecimento/lembrança que configurou a vida dos afrodescendentes brasileiros(as).

O segundo conto escolhido, nomeado "Maria Déia", revela um período de vida significativo da protagonista, desde a infância até a terceira idade. De nome homônimo à narrativa, a personagem principal vive em uma favela do Rio de Janeiro com seis familiares. Deinha, como é chamada, relata a mudança de sua família de um subúrbio para outro, em busca da reconstrução de suas vidas, após a desocupação forçada pela polícia do morro onde moravam. Ao longo de vinte e duas páginas, a autora trabalha com vários temas, sendo um deles a humanização dos moradores das comunidades periféricas, como aparece no relato da narradora ao falar sobre os estudos no colegial na época em que podia estudar:

No segundo ano do ginasial, escrevi, produzi
e dirigi uma peça 'Nega República'. E fiquei,
claro, com o melhor papel. As outras meninas,
insossas e coadjuvantes, mesmo sem terem
brilho no espetáculo, adoraram os aplausos.
Isto lhes bastara. Adorei a sensação de popu-
laridade e poder (VIEIRA, 2017, p. 78).

A autora, nesse excerto, dá voz a sujeitos que, em geral, são silenciados no cânone literário, mostrando que esses também desenvolvem conhecimentos e habilidades diante das oportunidades. Não por acaso, o espaço de inscrição e valorização de Deinha é a arte teatral - nela, torna-se autora e atriz de seu enredo, experimentando a furtiva, mas impactante, sensação de "popularidade e poder".

A narrativa, assim, revela a força da ficção dentro da ficcionalidade do conto, ainda que, emoldurando o enredo, encontre-se a seguinte dedicatória: "Para Carlos José, que sabe a verdadeira história" (2017, p. 73). Conforme bem observa Fonseca (2015), esse elemento promove uma redução das fronteiras entre o mundo da vida e o da ficção, ou, dito de outro modo, ao mesmo tempo em que o conto se constitui ficcionalmente, também carrega traços de referentes presentes no mundo vivido (RICOEUR, 1977).

Outra ocorrência dessa proximidade é a similaridade da protagonista Maria Déia com a personagem histórica Maria Bonita - sertaneja e baiana cujo nome completo é Maria Gomes de Oliveira -, também conhecida como Maria Déa, que foi a primeira mulher a ingressar no cangaço (VALQUER, 2016). Ambas as Marias, nascidas em contextos periféricos, representam um perfil de mulher que desmistifica o papel social fixado pela sociedade no viés machista e sexista, visto que desempenham funções e ocupam espaços antes delegados apenas ao sexo masculino, como a liderança de grupos/associações ou a coordenação destes ao lado de seus companheiros. 
Ao longo da narrativa, porém, o que prevalece são situações que levam à reflexão das desigualdades e preconceitos enfrentados pelos/as negros/as, como, por exemplo, a falsa democracia racial brasileira (CARNEIRO, 2011). Ao contrário, o racismo é revelado em tintas formes, como neste fragmento: "Aos cinco anos, dei dentada ao menino que me chamou: Neguinha, gambá" (VIEIRA, 2017, p. 78). Considerando a atual sociedade brasileira, na qual uma parcela julga não haver mais preconceito racial, a narrativa de Lia Vieira suscita uma reflexão mais cautelosa e crítica.

Em outros trechos, a autora aborda a vulnerabilidade social da população negra e pobre no Brasil, alerta para a falta de assistência pública e descortina as consequências das desocupações forçadas. Pela importância dessa temática, apresentamos duas citações mais longas do conto:

[...] Ouviram-se os primeiro estrondos, ficaram brilhantes os olhos, antes sonolentos; num relâmpago, a imediata compreensão. Os barracos sucumbiram ante as escavações. Chão, telhados, bacias de peixes, abóboras, roupas, utensilios, trapos, tudo misturado... Tudo sendo levado a roldão. O gemido dos moribundos, os gritos desesperados das mulheres, o lúgubre uivar dos cães. Alguns ainda dormem [...]. Outros jazem em meio à escuridão do penhasco, cuja boca imensa se abre embaixo, lá no fundo. .

[...]

O Morro do Santo Antônio não existe mais O quadrilátero no Centro do Rio abriga hoje: O BNDES, o prédio da Petrobrás, a Caixa Econômica Federal e a Catedral Metropolitana do Rio de Janeiro. O local sepulta vidas dadas em sacrifício. O convento de Santo Antônio continua lá, como um Palatino, numa colina. Testemunha viva da história e das consequências sociais e econômicas que a especulação imobiliária acarreta (VIEIRA, 2017, p. 83-84).

Esses fragmentos se entrelaçam na configuração do processo de favelização do Rio de Janeiro, iniciado no final do século XIX, bem como do contexto ditatorial da década de 1960, quando comunidades inteiras foram destituidas de seus lares, por interesses econômico-financeiros da elite brasileira. De acordo com Brum (2013), um dos projetos do governo militar instaurado com o golpe de 1964 era remover todas as comunidades que habitavam regiões próximas aos grandes centros, promovendo uma "limpeza" na paisagem urbana. Com a promessa de serem transferidas para núcleos habitacionais organizados, comunidades inteiras foram abandonadas sem qualquer tipo de assistência.

Dessa forma, o conto mostra como os(as) sobreviventes desses desumanos processos de remoção foram obrigados/as a ocupar outras zonas periféricas, restando aos próprios moradores encarregarem-se da organização e do cuidado com as novas e precárias instalações. Essa situação é representada pelas ações da personagem Greg, que se torna líder comunitário:

\begin{abstract}
Greg estava cada vez mais comprometido com atividades da Associação, botar água no morro, cadastrar e investigar os recém-chegados, providenciar óculos, aparelhos auditivos, cadeira de rodas, toda sorte de ocupações. [...] O morro crescia a olhos vistos: pequenos armazéns e escolas, quadra de esportes e um clube social (VIEIRA, 2017, p. 88).
\end{abstract}

Por outro lado, Greg tornou-se também uma ameaça para os donos do capital e passa a ser perseguido por ter adquirido poder e representação junto à comunidade. Situações análogas ocorriam durante a ditadura militar, principalmente após o Ato Institucional Número 5 (1968), que garantia poder absoluto aos militares, periodo no qual as associações comunitárias foram severamente reprimidas, perdendo o direito de expressão e de reivindicação por melhores condições de vida. No conto, a protagonista Maria casa-se com Greg, que acaba sendo morto pela polícia dentro da própria residência na frente da esposa, resultado das perseguições. Com esse cenário, a autora retrata, mais uma vez, a banalização da vida desses moradores, bem como os traços da repressão instalada desde o regime ditatorial.

Em suma, o conto evidencia o desprezo lançado às vidas negras em nosso país, conforme canta a música A carne (1998), de Seu Jorge, Marcelo Yuca e Wilson Capelletti: "A carne mais barata do mercado/ É a carne negra/ Que vai de graça pro presídio/ E para debaixo do plástico/ E vai de graça pro subemprego/ E pros hospitais psiquiátricos". Trata-se do genocidio do povo negro no Brasil, confirmando a banalização social dessas vidas; porém, ao mesmo tempo, 
como desfecho dessa narrativa de Lia Vieira, a protagonista Maria Déia, que desde o início da vida lutou contra as desigualdades sociais, evidencia a força e resistência desse povo, e em especial da mulher negra que, não raras vezes, precisa lutar sozinha: "De repente, eu me sinto só como uma loba, que fora da alcateia, é mais ativa, é mais feroz, é mais forte e que se compraz com a solidão contida" (2017, p. 94).

No terceiro conto selecionado, "Operação Candelária", o entrecruzamento da ficção com a história afirma-se desde o título, que remete ao assassinato de oito jovens negros, no centro do Rio de Janeiro, em 1993, fato que marcou o histórico de violência contra essa parte da população brasileira. A narrativa expressa, assim como afirma Ginzburg (2002 apud PESAVENTO, 2013, p. 32, grifo nosso), que a ficção literária é fomentada a partir de um real. Esse real está contextualizado por vários espaços da capital carioca: "[Na] Avenida Presidente Vargas e a Rua Miguel Couto, privilegiada localização de Rio de Janeiro [proximidades da Igreja da Candelária]" (VIEIRA, 2017, p. 55); nos eventos correlatos ao enredo: "[...] Divididos entre uma esquina e outra, meninos e mendigos, sem agasalho, enfrentavam o frio" (2017, p. 60); e também na faixa etária das vítimas: "[o tenente] deteve-se diante do amontoado de corpos. As idades variavam entre quinze e dezoito anos presumiveis" (2017, p. 66).

Mais uma vez, se faz presente a temática da vulnerabilidade social e a violência policial sofrida pela população carente, nesse caso, as pessoas em situação de rua, o que fica evidenciado, nos diálogos entre as personagens Capitão Sargento, Besta/1 e Besta/6:

Vocês não devem recear fazer barulho, já que a região é deserta. Várias medidas foram tomadas. As mensagens nos serão transmitidas numa frequência. Com exceção de Besta/1, nenhum de vocês saberá mais detalhes sobre a Operação até duas horas antes de ela começar. Isto guarda ainda mais a atividade. Devemos mostrar de uma vez por todas que sabemos proteger nossas instituições... - Uma geração que chega à maioridade sem um futuro decente, especialmente, tratando-se de negros [...] (2017, p. 64).
Esse excerto resume o planejamento da chacina, organizado por vários dias, sem levantar suspeitas, tornando explícito que o alvo da operação eram os(as) desvalidos(as) das ruas, principalmente negras e negros, e revela a crueldade do extermínio que estava para ser cometido. Nessa direção, a narrativa literária produz o efeito de verossimilhança, do qual trata os estudos ricoeurianos, porém, sem a pretensão de perseguir a comprovação de uma veracidade.

Observamos, ainda nesse sentido, a passagem que enfatiza o quanto os jovens negros são tratados pelas autoridades como ameaças à sociedade, conforme dito por um dos oficiais, em momentos que antecedem à chacina: "Levou mais tempo do que o necessário para averiguar os dois pivetes [...] - Pivetes, hein? Um dia, ainda porão este país em perigo" (VIEIRA, 2017, p. 57). O termo "pivete" é utilizado em sentido pejorativo pelos policiais, enclausurando o(a) negro(a) em categorias excludentes, em consonância ao que Mbembe (2014, p. 28) chamou de figuras do "em excesso" e da "dissemelhança" com o outro.

Assim também, a certeza de impunidade pelos agentes da operação ressalta a pouca importância investigativa dada a casos que envolvem pessoas negras, e em situação de rua:

\begin{abstract}
Sabe tenente, como esperávamos, não há vestígios de qualquer espécie. [...] E as testemunhas, onde estão? - Estão em choque... foram levadas para uma clínica particular... sob custódia, é claro. - Mas não as interrogaram? - Suas primeiras declarações foram incoerentes, controvertidas. Estão sofrendo dos nervos (2017, p. 67).
\end{abstract}

A chacina repercutiu mundialmente, e entre os acusados estavam policiais militares, alguns deles posteriormente condenados, mas que não cumpriram a pena completa. A morte dos oito jovens negros demonstra a contínua violência policial sofrida por negros da preferia e moradores de ruas, como em outros vários casos de mesma motivação, de que são exemplares o assassinato de onze jovens da periferia do Acari, em 1990, e dos vinte e um residentes do morro de Vigário Geral no mesmo ano: "crimes pelos quais foram acusados, respectivamente, cinco, sete e 49 
policiais militares, [o que denota] uma escalada nesse envolvimento" (LEITE, 2000, p. 75).

No conto, a história está dividida por marcações em dias e horários que vão até a data do massacre, assimilando-se à reconstituição de um crime. Essa configuração do tempo é outro dos pontos em que a história e a literatura se entreveem, pois: "Seja [...] o que se passou, no caso da História, ou que poderia ter se passado, mas que realmente se passa, para a voz narrativa da Literatura, este tempo se constrói como uma nova temporalidade" (PESAVENTO, 2003, p. 33).

Em outros diálogos é notável a tentativa de negação de humanidade à população negra e em situação de rua, mesmo em relação às crianças. Os comandantes da operação almejavam rejeitar e inibir as lutas e as manifestações por garantia aos direitos da criança e do adolescente, conforme percebemos na fala de uma das personagens, em tom irônico: "[...] em 1992. a ladainha incluía algo: o Estatuto da Criança e do Adolescente. Era preciso desestimular esses discursos" (VIEIRA, 2017, p. 60). Aproximando-se do fato social e histórico, o fim do conto mostra que o caso não foi investigado com afinco e os responsáveis não foram punidos.

No último conto selecionado, encontramos a abordagem da afetividade na terceira idade. "Os limites do Moinho", protagonizado por Domingas Soares, oferece um contraponto à visão romantizada de amor e de relacionamento. Domingas é uma escritora negra independente e bem-sucedida, que viaja para Havana, Cuba, a fim de participar de um evento de escritores e de artistas. Ao conhecer e se interessar por um cineasta, a personagem demonstra consciência de si no mundo, evidenciando a experiência adquirida com a idade: "Aos sessenta anos, temos a consciência dos limites, vivenciamos mais as impossibilidades do que as possibilidades - este é o grande desafio" (2017, p. 42). Nesse sentido, a história de amor, que ocorre durante a viagem, expõe que ambos aproveitam a oportunidade de vivenciar uma relação saudável sem cobranças excessivas ou abusivas. Esse desenrolar da história fratura a cultura machista, na qual perdemos "muito tempo ensinando as meninas a se preocupar com o que os meninos pensam delas. Mas o oposto não acontece" (ADICHIE, 2015, p. 27).

Essa premissa patriarcal que ensina as mulheres a serem submissas e a se preocuparem em sempre agradar o sexo masculino é subvertida no conto pelas atitudes de Domingas. Além disso, ao abordar a temática da afetividade direcionada aos(às) afrodescendentes, a autora evoca discussão importante, visto que, historicamente: "[...] a prática de reprimir os sentimentos como estratégia de sobrevivência continuou a ser um aspecto na vida dos negros, mesmo depois da escravidão" (HOOKS, 1994, p. 190). Nesse sentido, ao apresentar uma história afetuosa entre um homem negro e uma mulher negra, o conto corrobora com a valorização e humanização dessas identidades.

Além disso, a narrativa também aponta para a importância da emancipação feminina, mas, nessa trajetória, importa destacar que o significado de emancipação feminina é diferente para negras e brancas, pois, também historicamente, as mulheres negras sempre trabalharam fora de casa, sem o direito de usufruir ou priorizar a vivência familiar, enquanto os papéis sociais de mãe, esposa e dona de casa sempre foram impostos às mulheres brancas. Contrariamente a esses dois lados, o conto apresenta as múltiplas identidades da protagonista, profissional e pessoalmente emancipada.

Aprofundando a temática, a autora aborda a dificuldade que a sociedade em geral, e o sexo masculino especificamente, ainda hoje, têm para a aceitação/reconhecimento da mulher bem-sucedida que, mesmo tendo qualificação,por vezes superior e em vários níveis - ainda é subjugada a papéis sociais reducionistas. Essa questão também influi na afetividade, uma vez que a cultura machista ainda impulsiona o homem, de modo genérico, a não se relacionar com mulheres bem-sucedidas por não aceitarem ter uma companheira com autonomia financeira e gerencial. No conto, a protagonista demonstra a percepção dessa perversa situação, quando a mulher está orientada para a realização e a 
independência: "Por mais alto que seja o preço que se pague, está-se sempre sozinha quando se chega a algum lugar" (VIEIRA, 2017, p. 27).

Por fim, outro aspecto tratado no conto é a condição de escritora diante do sistema hegemônico, perceptivel até os dias atuais: "Mesmo sabendo como são duras as regras do jogo, é preciso transgredir essa maquinaria cultural hegemônica e estreita, buscado uma arte crítica, resistente e revolucionária. Em luta permanente com a renovação" (2017, p. 32). Essa consciência do sistema exclusivista demarca a falta de representação de negros(as) no cânone, ainda carregado de estereótipos negativos. Situação que impulsiona o debate acerca da necessidade de uma vertente literária que valorize essas identidades e as represente, como se empenha a fazer a literatura afro-brasileira.

\section{Considerações finais}

No decorrer desta análise, reafirmamos que os discursos literário e histórico são construções sociodiscursivas que podem se entrelaçar de formas diversas. Só as mulheres sangram (2017), de Lia Vieira, demonstra substancialmente a forma como a ficção dialoga com real, ao abarcar, entre muitos temas críticos, a violência sofrida por jovens negros(as) moradores/as de ruas elou) das comunidades periféricas.

Além de tecer as experiências das protagonistas em várias temáticas, a autora reforça a proposta que percebemos no decorrer da obra: contemplar amplamente as vivências da população negra, em especial a feminina. Essa tônica é expressa a partir do título da obra analisada, que faz relação direta com as personagens femininas. O verbo sangrar, no presente da terceira pessoa feminina do plural, é utilizado como uma metáfora para o sofrimento vivido pelas mulheres, simbolizando as perdas acumuladas e violências sofridas ao longo das suas histórias de vida. Outrossim, sangrar corresponde também ao fenômeno biológico que acompanha as mulheres em vários ciclos no desenrolar da própria vida dessas personagens: desde o início da vida fértil ao momento do parto.
De forma abrangente, os quatro contos analisados promovem o resgate da história e da cultura afro-brasileira. Além disso, mantêm diálogo constante com a realidade histórica na qual se inserem, dando ênfase à afetividade, à ancestralidade, e à emancipação feminina, valorizando a identidade e o lócus enunciativo especialmente da mulher negra. Com efeito, os referidos contos fomentam reflexões sobre a necessidade de enfrentamento das desigualdades e aos fluxos hegemônicos, contribuindo na produção de novas perspectivas de mundo.

Em face disso, confirmamos que a existência de vertentes literárias que ressaltam a identidade negra e atuam na quebra do silenciamento imposto, promove a revisão das narrativas canônicas, abrindo espaço à representatividade da mulher negra na literatura. Esse novo cenário, no âmbito dos estudos culturais/literários, considera as relações históricas e socioculturais de forma imbricada, e contextualiza as vivências desses individuos a partir das alteridades que os compõem. As narrativas afro-brasileiras trazem, ao plano literário, o sujeito negro/a representado longe das fórmulas reducionistas e homogeneizantes do cânone.

\section{Referências}

ADICHIE, Chimamanda Ngozi. Sejamos todos feministas. Tradução de Christina Baum. São Paulo: Companhia das Letras, 2015

BRUM, Mario. Favelas e remocionismo ontem e hoje: da Ditadura de 1964 aos Grandes Eventos. O Social em Questão, Rio de Janeiro, n. 29, p. 179-208, jan. 2013. Disponivel em: http://osocialemquestao.ser.puc-rio.br/ media/8artigo29.pdf. Acesso em: 3 mar. 2019.

CARNEIRO, Sueli. Racismo e sexismo e desigualdade no Brasil. São Paulo: Selo Negro, 2011.

CUTI, Luiz Silva. Literatura negro-brasileira. São Paulo: Selo Negro, 2010.

DAVIS, Angela. Mulheres, raça e classe. Tradução de Heci Regina Candiani. São Paulo: Boitempo, 2016.

DUARTE, Eduardo de Assis. Literatura Afro-brasileira: um conceito em construção. In: AFOLABI, Niyi; BARBOSA, Márcio; RIBEIRO, Esmeralda (org.) A mente afro-brasileira. Trenton-NJ, EUA/Asmara, Eritréia: África World Press, 2007. p. 103-112. 
DOMINGUES, Petrônio. Como se fosse bumerangue: Frente Negra Brasileira no circuito transatlântico. Revista Brasileira de Ciências Sociais, São Paulo, v. 28, n. 81, p.156-256, fev. 2013. Disponivel em: http://www.scielo. br/pdf/rbcsoc/v28n81/10.pdf. Acesso em: 22 jan. 2019

FONSECA, Maria Nazareth Soares (org.) Diálogos entre História e Literatura em obras literárias africanas e brasileiras. Revista Historiæ, Rio Grande, v. 6, n. 1, p. 243-267, 2015. Disponivel em: https://periodicos.furg. br/hist/article/view/5416. Acesso em: 18 abr. 2019

GINZBURG, Carlo. Mitos, emblemas, sinais: morfologia e história. São Paulo: Companhia das Letras, 2007.

HOOKS, bell. Vivendo de amor. Tradução de Maisa Mendonça. Ed. rev. Washington: Seal Press, 1994.

MIRIAM Alves - Dados biográficos. In: LITERAFRO. Portal da literatura afro-brasileira, Belo Horizonte, 6 jul. 2018. Disponivel em: http://www.letras.ufmg.br/literafro/ autoras/348-miriam-alves. Acesso em: 7 jan. 2019.

LEITE, Márcia Pereira. Entre o individualismo e a solidariedade: dilemas da política e da cidadania no Rio de Janeiro. Revista Brasileira de Ciências Sociais, São Paulo, v. 15, n. 44, p. 73-90, out. 2000. Disponivel em: http://www.scielo.br/pdf/rbcsoc/v15n44/4148.pdf. Acesso em: 9 jan. 2019.

MATA, Inocência. Estudos pós-coloniais: desconstruindo genealogias eurocêntricas. Revista Civitas, Porto Alegre, v. 14, n. 1, p. 27-42, jan. abr. 2014. Disponivel em: http://revistaseletronicas.pucrs.br/ojs/index.php/civitas/article/view/16185/10957. Acesso em: 27 jun. 2018.

MBEMBE, Achille. Crítica da razão negra. Tradução de Marta Lança. Portugal: Antígona, 2014.

OLIVEIRA, Luiz Henrique Silva de; RODRIGUES, Fabiane Cristine. Panorama editorial da literatura afro-brasileira através dos gêneros romance e conto. Em Tese, Belo Horizonte, v. 22 n. 3. p. 90-107, set./dez. 2016. Disponivel em: http://www.periodicos.letras.ufmg.br/index.php/ emtese/article/view/11269/10712. Acesso em: 24 de jan. 2019.

PESAVENTO, Sandra Jatahy. O mundo como texto: leituras da História e da Literatura. Revista de História da Educação, Porto Alegre, n. 14, p. 31-45, 2003.

Disponivel em: https://seer.ufrgs.br/asphe/article/ view/30220/pdf. Acesso em: 12 fev. 2019.

REIS, Maria Firmina dos. Úrsula. Porto Alegre: RS: Zouk, 2018.

RICOEUR, Paul. Tempo e narrativa. Tradução de Roberto Leal Ferreira. Campinas: Papirus, 1997. t. III

RIBEIRO, Djamila. O que é lugar de fala? Belo Horizonte: Letramento, 2017.

SILVA, Jorge Mário da; SANTA ANA, Marcelo Fontes do Nascimento Viana de; TASSANO, Ulisses Capelletti. A carne. In: FAROFA CARIOCA. Moro no Brasil. Rio de Janeiro: Polygram, 1998. 1 CD. Faixa 7.
VALQUER, Leandro. A história de Maria Bonita. Raça, out. 2016. Seção: Especiais. Disponivel em: https:// revistaraca.com.br/a-historia-de-maria-bonita. Acesso em: 22 mar. 2019.

VIEIRA, Lia. Só as mulheres sangram. Belo Horizonte: Nandyala, 2017.

\section{Elizane Souza dos Santos Henriques}

Mestra em Letras: Linguagens e Representações pela Universidade Estadual de Santa Cruz (UESC), em Ilhéus, BA, Brasil; graduada em Comunicação Social - Rádio e TV, pela Universidade Estadual de Santa Cruz (UESC), em Ilhéus, BA, Brasil.

\section{Inara de Oliveira Rodrigues}

Doutora em Letras pela Pontificia Universidade Católica do Rio Grande do Sul (PUCRS), em Porto Alegre, RS, Brasil; mestre em Letras pela mesma instituição; bacharel em História pela Universidade Federal do Rio Grande do Sul (UFRS), em Porto Alegre, RS, Brasil; realizou estágio pós-doutoral em Literatura na Universidade Federal do Rio Grande do Sul (UFRS), em Porto Alegre, RS, Brasil. Professora titular da Universidade Estadual de Santa Cruz (UESC), em Ilhéus, BA, Brasil, atuando no Curso de Letras, no Programa de Pós-Graduação (Mestrado e Doutorado) em Letras: Linguagens e Representações e no Mestrado em História: Atlântico e Diáspora Africana.

\section{Endereço de correspondência}

Elizane Souza dos Santos Henriques

Edificio Giuseppe Verde

R. Rosenaide, 248, apto. 301

Zildolândia, 45600-702

Itabuna, BA, Brasil

Inara de Oliveira Rodrigues

Rua Marquês de Paranaguá, 200

Caixa postal 309

Centro, 45653-970

Ithéus, BA, Brasil

Os textos deste artigo foram revisados pela Poá Comunicação e submetidos para validação das autoras antes da publicação. 